\title{
Unethical Behaviour in Nigerian Organizational Settings: Its Evolution, Dimensions and Impact on National Development
}

\author{
Leonard I. Ugwu, Ph, D. \\ Department of Psychology \\ University of Nigeria, Nsukka, Nigeria \\ E-mail: leonify@yhoo.com
}

\begin{abstract}
A disturbing but unavoidable fact of organizational life is that employees sometimes engage in ethically questionable activities that harm their companies, their co-workers, or the general public. Unethical behaviour in the workplace can take different dimensions ranging from lying, cheating, stealing, sabotage, corruption, to hiding or destruction of official documents. The paper traced the origin of employees' unethical behaviour to the undesirable activities of the colonialists and the corresponding employees' tacit resistance that manifested in the form of unethical behaviour. The employees' undesirable activities were designed to reduce the perceived input-outcome differentials that favoured the colonialists. The questionable ethical activities of the employees have the potential of slowing down the pace of economic development and tarnish the image of the organizations, with gross reduction in public confidence, which invariably deter investors. Consequently, the economic costs of such unethical behaviour in the workplace cannot easily be estimated, but it is likely that billions of Naira is lost annually. The paper contends that individual value system, organizational practices, and wider external environments are some influential factors of unethical behaviour, and therefore, recommends periodic workshops, seminars, and ethics training for employees so that they can internalize high ethical standards in their daily behaviour.
\end{abstract}

Keywords: Unethical behaviour, Individual variables and organizational settings

\section{Introduction}

Ethically questionable behaviour in Nigerian organizational setting is not a new phenomenon. It is as old as the first established formal organisation in Nigeria. Employees' unethical behaviour in Nigerian is rooted in the activities of the colonialists whom Nigerian employees modelled after. For instance, in the pre-colonial era of Nigeria, many ethnic groups were organized into separate and autonomous/political societies coterminous with the village (Geschiere, 1999). But when the colonialists penetrated, in what is today referred to as the sovereign state of Nigeria, they settled in designated areas for trade and administrative conveniences and established formal organizations. The native Nigerians were recruited into these organisations and were paid in piece-rate. The work-and-pay system introduced by the colonialists became attractive to Nigerians from diverse ethnic groups. Consequently, people from diverse ethnic groups moved in droves to the settlement areas in search of employment in the newly established firms. In order to realize the goals of the organisation that were hinged on profit maximization (Toure, 2003), the colonialists formulated prescribed rules of the organisation. These rules were designed to pigeonhole employee behaviour towards realising the organizational goals.

Working under the confines of the organisational rules and regulations, the native Nigerians, no sooner than later, realised that there existed discrepancies between their inputs and their rewards, with their perceived inputs being higher than their remunerations. To reduce inequity arising from input-outcome discrepancies and tacitly resist the perceived exploitative tendencies of the colonialists, Nigerian employees at the time embarked on questionable ethical behaviours such as embezzlement, pilfering that earned them reward related vantage position (Bichi, 2006).

At the dawn of independence in Nigeria, many employees had imbibed the Western-oriented managerial skills, which provided them with the capacity and knowledge to manage already existing formal organisations bequeathed to them by the colonialists. Shortly after independence, many of these firms or companies were indigenized, which afforded Nigerians full autonomy and control over those firms. In addition, Nigerians established many other companies for Nigeria. 
Nigerian managers as well as employees were ardent disciples of the colonialists, which made the extension of the colonialists' exploitative practices and the corresponding employees' resistance to such perceived exploitations become recurring decimals. However, this situation was aggravated by the activities of the successive military regimes in Nigeria (spanning over 29 year), which subdued the rule of law, facilitated the wanton looting of the public treasury, and instituted a secret and opaque culture in the running of government businesses. The result was gross poor economic management, embezzlement, corruption, and employees' desire to circumvent the formal organizational ethical conduct.

\section{What is unethical behaviour?}

Unethical behaviour is plagued with definitional dilemma. This stems from the fact that writers tend to confuse unethical behaviour with morality and illegality of acts. The three variables, though interrelated, are slightly distinct. Unethical behaviour is defined as behaviour that brings harm to, and that is illegal or morally unacceptable to the larger society. By this definition, lying, corruption, cheating, stealing, divulging official secrets or interpersonal aggression would be examples of such behaviour.

Although there is a legal component to ethical behaviour, it does not simply mean that because an action is not illegal that it is necessarily ethical. For instance, the action of an employee who takes longer time than necessary to do a job or who makes personal telephone calls on company time may not be considered illegal, but many people would consider one or two of them to be unethical. Ethical consideration goes beyond the legality of act, it extends to personal values - the underlying beliefs and attitudes that help determine individual behaviour (Ogbuehi, 1998). The extent to which values vary among people, to that extent we can expect different interpretations of what behaviour is ethical or unethical. In practice, therefore, ethical behaviour is what is accepted as "good" and "right" as opposed to "bad" or "wrong" in the context of the governing moral code of any given industry (Chaloupka, 1987). Regarding morality and ethics, the difference between the two is that morality has to do with universally held belief in certain values and norms, whereas ethnics is a local matter that seeks agreement among people that certain beliefs and values are worth holding. Furthermore, ethics is domain specific.

\section{Predisposing factors of unethical behaviour}

It is very difficult to pinpoint all the predisposing variables of unethical behaviour in the World of work in Nigeria, neither is it easier to associate unethical behaviour with a single factor. Many researchers have attempted to isolate all the variables that facilitate or inhibit unethical behaviour. Full knowledge of factors influencing unethical behaviour may help management to better deal with them in future. These factors can be classified into three categories:

\section{1. individual variables}

2. the organizational practices, and

3. the environmental factors.

\subsection{Individual variables}

Individuals are not island onto themselves. They grew up with other members of the society where they internalized the norms and values of the group members. In the World of work, the story is not different. Employees come to the workplace with their needs, desires, expectations, cultural values, and even with their idiosyncrasies. Their personal experiences and background affect the way they perceive and obey the work ethics. Family needs (financial and otherwise) contribute to a large extent in influencing employee's ethical conduct in any given circumstance. Employees whose moral values conflict with the company's ethical standard will strive to maximize their self- interests at the expense of the organizations' general overall interest. Many researchers (e.g. Ugwu, 2009; Aquino \& Reed, 2002; Summer, Welsh \& Gubman, 2009; Lim, 2002) have studied the predictors of unethical workplace behaviour. Results showed that moral identity, age, large family size, and organization's formal and informal ethical practices are influential factors of unethical behaviour. But one strong factor that has been identified as the major influential factor of unethical behaviour is the presence of incentive for behaving unethically. Incentives associated with behaving unethically have made many employees face ethical dilemma in their course of decision- making. Problems in dealing with special gifts, entertainment, kick backs, and excessive loyalty has blurred objective decision- making and eroded codes of conducts. In some cases, the major source of pressures for subordinates' unethical behaviour to engage in unethical activities such as supporting incorrect view points, signing false documents, over-looking the superior's wrongdoings, and doing business with the boss's friends. In all these instances, an employee with low moral standards will cave in and indulge in unethical behaviour in anticipation of rewards or incentives from the superiors, for according to Andrews (1989), "people will do what they are rewarded for doing" p. 101. 


\subsection{Organizational practices}

The activities of the employing organizations may violate the psychological contract, which organizations entered into with employees. For instance, employees perform their duties in the organization in return for rewards at the end of the month. When employers fail to pay workers their salaries and other entitlements, and when workers stagnate in one grade level with little or no prospects for advancement, the stage is set for employees to circumvent the rule of law and device survival strategies without any ethical consideration (Ugwu, 2009; Bichi, 2006). Imagine, for instance, when the management of an organization embarks on activities that are unethical, such as baking industry that deceives the public that their bread is bromide-free or a manufacturing company that advertises that their new product is "improved" while it is not. As employees watch their organization deceive the public, they may rationalize and justify their own misconducts.

Formal policy statements and written rules are also very important in establishing an ethical climate for the organization as a whole. When organization's policy statements have human face and the superior officers respect the written rules with no "sacred cows" in the organization in respect of the violation of these rules, employees' ethical behaviour will be reinforced.

\subsection{The environmental factors}

Organizations are microcosm of the larger environmental contexts. Organizations operate in external environments composed of competitors, government laws and regulations, and social norms and values, to mention but a few (Ogbuehi, 1998). To maximize profits and survive in the competitive markets, organizations may embark on questionable ethical behaviour such as setting targets for their employees, irrespective of the means through which these employees reach the targets. A case in point is the activities of some of the "second generation" banks where employees in the marketing sections are required to hit" certain financial targets. Government laws define appropriate behaviours for organizations and their members regulate these behaviours and keep them within acceptable standards. Apart from the government activities in regulating the behaviours of the management, the prevailing social values also influence what happens in many organizations. A society where corruption, stealing, kidnapping, and other social ills have taken front seat is bound to influence what happens in work organizations that are just a subset. Commenting on the influence of larger society in determining the ethical behaviour of employees in work organizations Stearns (1981) says:

"it is ironic that, in a country where people are murdered, kidnapped, raped and viciously attacked by the hour, there is still room to worry about ethical issues in the illegal copying of CDs" (p. 26).

An inference that could be drawn from the above quotation is that what is happening in the macro-environment far outweighs what we devote our time discussing today. In Nigeria, the scenario is the same, if not, worse. Millions of naira is lost as we blinker and the Nigerian employees belong to the society where unethical behaviour is treated with fanfare.

\section{Its impact on national development}

Lim (2002) reported that protecting organizations against unethical activities is also costly as illustrated by the estimated $\$ 7$ billion incurred by organizations to install security gadgets to guard against such activities. What is the fate of Nigeria if that is the case in the developed countries like America? The effects of unethical activities on nation's socio-political and economic development cannot be easily estimated in Nigeria. Lipset and Lenz (2000) note that unethical activities of the employees reduce the level of investment as it adds to investment risk. Corruption which is one aspect of unethical behaviour could also be expected to reduce growth by lowering the quality of public infrastructure and services, decreasing tax revenue and causing talented employees to engage in rent-seeking rather than productive activities. Corruption has really affected many of the business climates in Nigeria. Corruption disrupts governance, reduces the provisions of services by the government and its institutions. Impaired governance in turn, reduces capital and public trust in governance institution; this reduces the public fund available to support effective economic, social, political and technological growth programs (Bichi, 2006). By improving economic governance both in public and private organizations, Nigeria can set herself on the path towards attracting new investors and achieving sustainable economic growth. In this regard, it is especially important that government should implement a transparent regulatory framework governing public safety and public infrastructure.

Besides, questionable ethical behaviour breed distrust between management and employees, creates suspicion, and negatively impacts on capital accumulation that would have been ploughed back to the business. Furthermore, unethical behaviour in the world of work could negatively impact on income distribution and consequently creates income inequality, which exacerbates poverty. The situation may bring the nation into a vicious cycle since poverty has the potential of engendering corruption and corruption inhibits the economic growth of any nation. Questionable activities of employees in organization may also inhibit skill acquisition, 
which can slow the pace of the nation's technological development. Managers may channel their efforts towards protecting their organization from the undesirable activities of the employees thereby paying less attention to the program that will improve the skills of employees.

\section{Ways to improve ethical standards in workplace}

Nigerian managers have enormous role to play in maintaining high ethical standards in their firms. Some of the most important efforts in this area should involve:

1. clarification of ethical behaviour

2. ethics training

3. whistle - blower protection

4. top management support for ethical behaviour, and

5. management maintenance of strong ethical cultures

\subsection{Clarification of formal ethical behaviour}

Employees may violate formal ethical codes because of the ambiguous nature of the clause contained in the codes of conducts. In many organizations, for instance, formal ethical codes are written in ambiguous manner, using legal terms that are not simple to understand by many less educated employees. In this regard, ethics are violated due to ignorance of the demands of the ethics, although it is stated that ignorance of law is no excuse for its violation. In this respect, formal codes of conduct in work organizations should be written in clear and simple language so that employees can easily read and comprehend them with minimal difficulty.

\subsection{Ethics training}

Many organizations are required to design training programs in order to help them incorporate the company's high ethical standards into their daily behaviour. This could be achieved by organizing periodic seminars, workshops, and conferences to the employees where issues bordering on how managers would deal with ethical dilemmas are discussed. Many of these dilemmas arise as a result of time pressures and/or pressures from their co-workers or families. Thus, ethics training should be designed in order to equip the manager with high ethical standards so that they will be able to deal with ethical issues even when under pressure.

\subsection{Whistleblower protection}

Whistleblowers are persons who expose the misdeeds of others in organization in an attempt to preserve ethical standards and protect against wasteful, harmful, or illegal acts (Ogbuehi, 1998). Whistleblowers are most of the time faced with the risk of impaired career progress, termination of appointment, suspension, and other forms of organizational retaliation. It is even more appalling that Nigeria legal system offers little protection for the whistle blowers against "retaliatory action" from the superior officers. Such lack of legal protection prevents potential whistle blowers from exposing the unethical behaviours of the co-workers and superiors in the workplace. Worse still, some organizational barriers in the form of strict chain of command make it difficult for subordinates to bypass the superior and report the superiors' misdeed to the appropriate quarter. In some cases, where an employee reports informally the unethical behaviour of the superior officer to the management, he may be requested to put it in writing and of course route the letter through the immediate supervisor whose misdeeds are being questioned. Such organizational practices expose the identity of the whistle blower and, in addition, provides unethical employee with the fore knowledge of what awaits him. In this regard, employees whose ethical questionable activities would be investigated might begin to cover their misdeeds as they prepare their defence.

For organizations in Nigeria to remove these bottlenecks that block whistleblowers' exposure of unethical behaviour, Nigeria managers should involve staff members in periodic brainstorming session regarding the best strategy to adopt in shielding whistle blowers and protecting them against the retaliatory discharge of the superior officers whose misdeeds are under investigation. Companies should set up ethics committee composed of people of proven integrity, whose role is to deal with reported cases of questionable ethical activities.

\subsection{Management support for ethical behaviour}

Low-level employees model their behaviour after their superiors. Managers at the top echelon of the organization should set standards for the lower-level employees. For instance, when top managers use organizational resources for personal pleasure, the lower-level employees will imitate them and may even do worse things. This implies that an employee may be honest and of high moral character, but the undesirable behaviours of superiors and high level-managers may cause them to imitate the unethical practices of others or even adopt some themselves. Top management should therefore support high ethical conduct, define appropriate 
ethical behaviour for the entire organization and consistently engage in behaviour that will serve as the epitome of high ethical conduct.

\subsection{Maintenance of strong ethical culture}

Every organization has culture peculiar to it. Many of them are rooted in solid and consistent ethical code of conduct. Employee compliance to these codes of conduct is enforced differently by these organizations. In some organizations, compliance is compulsory and deviants are treated with severe sanctions, while in others, they are treated with levity. When organizations are consistently frowning at employees who violate the ethical codes, apply sanctions and punishment, and/or terminate them, depending on the gravity of the offence, compliance becomes high. Conversely, when top management engages in behaviour that is unethical or when there is a double standard in their actions, subordinates disobey the rule of law and rationalize for their unethical conduct.

\section{Conclusion}

Employees' unethical behaviour in Nigerian organizational settings has plagued the country's national development as huge sums of money are lost annually. But one other disturbing fact about its pervasive nature in the world of work is that researchers, policy makers and practitioners have failed to identify its predisposing variables. However, the paper classified these variables into three broad categories - individual variables; organizational practices, and environmental factors. The paper contends that one of these variables could not account for the complete, varied, and endemic unethical behaviour of employees in the world of work, but submits that employees' unethical behaviour is a function of the interrelationships between individual variables, organizational practices, and larger environmental contexts.

Furthermore, the paper submits that unethical activities of employees reduce the level of investment as it adds to investment risk. Lastly, the writer suggests ways to improve ethical standards in workplace, which includes clarification of ethical behaviour, ethics training, whistleblower protection; management support for ethical behaviour; and maintenance of strong ethical cultures.

\section{References}

Andrews, K. (1989). Ethics in practice. Harvard Business Review, (Sept-Oct), 99 - 194.

Aquino, K, Reed, S. (2002). The self-importance of morality. Journal of Personality and Social Psychology, 83, $1423-144$.

Bichi, A.A. (2006). Corruption and its Implication for National Development. Paper presented at the National Conference of Nigerian Psychological Association held at Uyo, Nigeria. $28^{\text {th }}-31^{\text {st }}$ August.

Chaloupka, G. (1987). Ethical responses: how to influence one's organization. Naval War College Review Winter, $80-90$.

Cherrington, J.O. \& Cherington, D.J. (1992). A menu of moral issues: one week in the life of the wall street. Journal of Business Ethics, 4, 255 - 265.

Geschiere, P. (1999). Formation of nationality identity in Africa. CODESRIA Bulletin, 3 \& 4, 85 - 86.

Lim, V. (2002). The IT way of loafing on the job: cyber loafing, neutralizing and organization justice. Journal of Organizational Behaviour, 23, $675-694$.

Lipset, S.M. Lenz, G. (2000). Corruption, culture. In L.E. Harrinson and S.P. Huntington (eds.) Culture Matters. New York: ST Martins Press.

Ogbuehi, A. (1998). Promoting international business ethics and integrity among Nigeria managers. Nigerian Institute of Management, 34, 10 - 15.

Sackmann, S.A. (1992). Culture of subcultures: an analysis of Organization knowledge. Administrative Science Quarterly, 37, $140-161$.

Steams, M. (1981). What are business ethics? Data Management, 19, 26.

Summer, M. Welsh, D. and Gubman, L. (2000). The ethical orientation of Russian entrepreneur. Applied Psychology: An International Review, 49, 688 - 708.

Toure, K. (2003). The imposition of British Colonial domination on the Sokoto Caliphate, Borno and neighbouring States, 1897 - 1914. A re-integration of colonial sources (Ph.D Thesis, Ahmadu Bello University, Zaria).

Ugwu, L.I. (2009). Personal and Organizational variables as predictor of unethical behaviour in the workplace. IFE Psychologia, 17(2), 250 - 262. 